\title{
User-dependent hygrothermal assessment and material parameter optimization for a wood- based construction under climate conditions of South Korea
}

\author{
Jiwon Seo ${ }^{1, *}$, and Frank U. Vogdt ${ }^{1}$ \\ ${ }^{1}$ Technische Universität Berlin, Berlin, Germany
}

\begin{abstract}
Hygrothermal simulation programs are widely used nowadays, but reliable results can only be achieved with the knowledge of input parameter values. This study shows how the difficulties, obtaining accurate material properties and specifying boundary conditions, affect the hygrothermal performance of the construction. A wood-based construction is investigated under climate conditions of South Korea. Sensitive material parameters and boundary conditions, which significantly influence the relative humidity in the construction, are identified by means of the method of Morris. The most influential material parameters are varied for specific boundary conditions using Latin Hypercube sampling, resulting in a wide range of relative humidity values $(\sim 51 \%$ until $\sim 99 \%)$ on OSB surface. Low relative humidity values on OSB are obtained with a Pareto-optimal material parameter set.
\end{abstract}

\section{Introduction}

ISO 13788 standard [1], based on Glaser method, is a stationary method for preventing moisture damage. Glaser method only considers water vapor diffusion transport and the standardized climatic conditions are simplified; the calculated result can significantly devia te from the real hygrothermal behaviour of the construction. Instationary simulation programs e.g. DELPHIN and WUFI ${ }^{\circledR}$ Pro are available, which can be used in the early design phase to determine reliable results of the hygrothermal behaviour. However, to achieve a reliable result and to interpret the result appropriately, reliable knowledge of input parameter values is necessary.

In this paper a hygrothermal assessment of a wood-based construction is carried out. The reference construction is recommended by practitioners for South Korean climate conditions. DELPHIN is used for automated hygrothermal simulation runs. In a first step, sensitive material parameters and boundary conditions, which significantly influence the relative humidity in the construction, are identified by means of the method of Morris. In a second step, boundary conditions and insensitive material parameters are fixed, and few sensitive material parameters are varied by Latin Hypercube sampling method. A range of material parameter values are studied rather than selecting few specific materials. Pareto-optimal material parameter set is identified.

\footnotetext{
* Corresponding author: jiwon.seo@gmx.de
} 


\section{Climate conditions of South Korea and wood-frame based construction}

The hygrothermal simulation is carried out under South Korean - city Incheon - climate conditions. In terms of hygrothermal behaviour not only winter, but also summer climatic condition is critical because of extremely hot and humid weather. Using weather data provided by WUFI ${ }^{\circledR}$ Pro, the hourly weather data of Incheon (South Korea) and Potsdam (Germany) in its hottest month are compared in Fig. 1. It shows that the summer climatic condition in Incheon is far from the indoor comfortable zone, defined by [2], and reversed water vapor diffusion from exterior to interior can occur in summer (Fig. 2).

The wood-based reference construction under assessment is described in Fig.2. This wall configuration is recommended in South Korea by practitioners from a passive house related association, PHIKO. There is only a rough standard [3] to plan moisture-damage free construction and the planners mostly rely on their experience. In order to avoid moisture damage from penetrated rain, an air layer is recommended between exterior finishing and membrane. Membrane (outside) is typically weather-resistive and watervapor-diffusive, while the membrane (inside) is water-vapor-resistant. The insulation material is installed inside and outside of structural board (OSB). Hence, OSB is not exposed to outdoor climate.

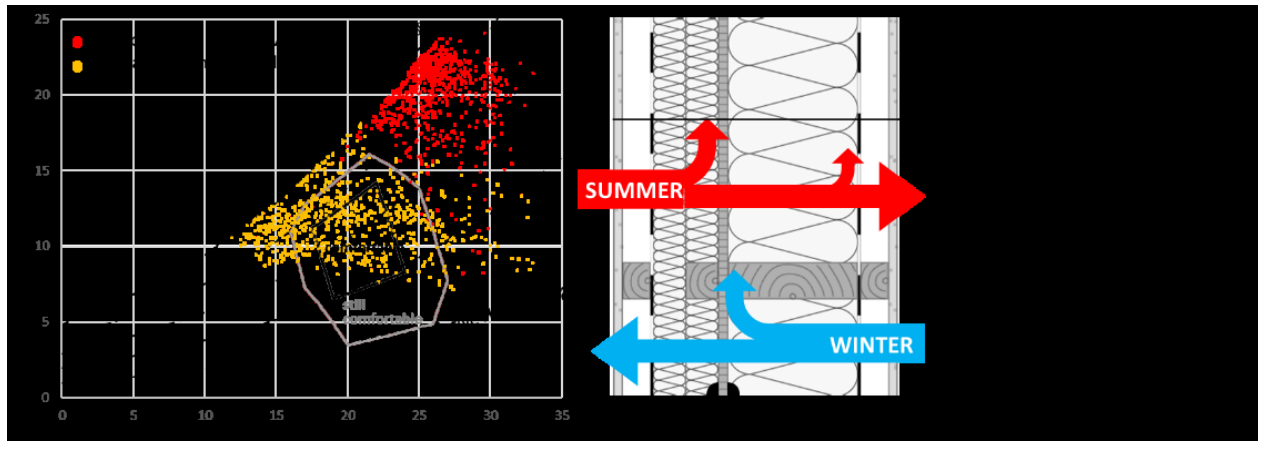

Fig. 1. Hourly outdoor climatic conditions in Fig. 2. Description of the reference wall configuration South Korea and Germany in its hottest month and moisture transfer direction in summer / winter

\section{Sensitivity Analysis: Method of Morris}

Because of temporally and spatially varying assessment criteria in the construction (e.g. relative humidity $\mathrm{rH}$ on OSB surface), varying boundary conditions (indoor / outdoor climate) and material parameter uncertainties, the hygrothermal assessment of a construction can be challenging for the planner. Sensitivity analysis (SA) based on automated hygrothermal simulation runs can be a useful tool for the planner to focus on important design parameters. SA is often used to identify inputs that have a significant impact on model outputs [4,5].

The method of Morris [6] is used in this study to identify sensitive parameters with few simulations runs. The mean value of a set of local derivatives, or elementary effects, for a defined parameter grid is calculated as a measure of global sensitivity. The possible grid levels of the $\mathrm{k}$ parameters are shown in Table 1. Each input parameter is divided in four equidistant levels within a defined range. The minimum and maximum values of each input parameter are based on available material data of existing material products (WUFI ${ }^{\circledR}$ Pro database) and possible indoor climate conditions. Each input parameter is perturbated oneat-time (OAT) along a randomly generated trajectory and for each perturbation one elementary effect is calculated. Hence, $\mathrm{k}+1$ simulation runs must be evaluated ( $\mathrm{k}$ parameters + start value). The procedure can be repeated $r$ times, i.e. in total $r(k+1)$ 
simulation runs must be carried out. As a result, $\mathrm{r}$ elementary effects for each parameter are available.

Table 1. Defined ranges of input parameter values (material / boundary conditions)

\begin{tabular}{|c|c|c|c|c|c|}
\hline \multicolumn{4}{|c|}{ Description } & Levels & Parameter \\
\hline \multirow{10}{*}{ Material } & \multirow{5}{*}{$\begin{array}{c}\text { Water Vapor Diffusion } \\
\text { Resistance Factor } \\
\qquad\left(\mathrm{W}_{0}\right)\end{array}$} & \multirow{5}{*}{ - } & Membrane (outside) & $\mathbf{1 0 0}, 400,700, \mathbf{1 0 0 0}$ & $\mu_{\mathrm{m} \text { out }}$ \\
\hline & & & Membrane (inside) & $\mathbf{1 0 0}, 3400,6700, \mathbf{1 0 0 0 0}$ & $\mu_{\mathrm{m} \text { in }}$ \\
\hline & & & OSB & $50,233,416,600$ & $\mu_{\mathrm{OSB}}$ \\
\hline & & & Insulation (outside) & $\mathbf{1 , 3 4 , 6 7 , \mathbf { 1 0 0 }}$ & $\mu_{\text {ins out }}$ \\
\hline & & & Insulation (inside) & $\mathbf{1 , 3 4 , 6 7 , \mathbf { 1 0 0 }}$ & $\mu_{\text {insin }}$ \\
\hline & \multirow{3}{*}{$\begin{array}{l}\text { Liquid Transport } \\
\text { Coefficient } \\
\text { at saturation } \mathrm{Dl}\left(\mathrm{W}_{\mathrm{f}}\right)\end{array}$} & \multirow{3}{*}{$\mathrm{m}^{2} / \mathrm{s}$} & OSB & $-12,-11-10,-9$ & $\lg \left(\mathrm{Dl}_{\mathrm{OSB}}\right)$ \\
\hline & & & Insulation (outside) & $-8,-7,-6,-5$ & $\lg \left(D l_{\text {ins out }}\right)$ \\
\hline & & & Insulation (inside) & $\mathbf{- 8 , - 7 , - 6 , - 5}$ & $\lg \left(D 1_{\text {ins in }}\right)$ \\
\hline & \multirow{2}{*}{$\begin{array}{l}\text { Moisture-related thermal } \\
\text { conductivity supplement } b_{\lambda}\end{array}$} & & Insulation (outside) & $0,2,4,6$ & $\mathrm{~b}_{\lambda \text { ins out }}$ \\
\hline & & & Insulation (inside) & $0,2,4,6$ & $\mathrm{~b}_{\lambda \text { ins in }}$ \\
\hline \multirow{3}{*}{$\begin{array}{l}\text { Boundary } \\
\text { Condition }\end{array}$} & \multirow{2}{*}{ Indoor Climate } & ${ }^{\circ} \mathrm{C}$ & Temperature & $18,22,26,30$ & $\mathrm{~T}_{\text {in }}$ \\
\hline & & $\%$ & Relative humidity & $30,45,60,75$ & $\mathrm{rH}_{\mathrm{in}}$ \\
\hline & Air Infiltration q50 & $\mathrm{m}^{3} / \mathrm{m}^{2} \mathrm{~h}$ & on OSB & $1,3,5,7$ & I \\
\hline
\end{tabular}

Table 2. Approximately calculated moisture-dependent building material parameter values

\begin{tabular}{|c|c|l|}
\hline Description & Equation for the approximation & \multicolumn{1}{|c|}{ Approximated value } \\
\hline $\begin{array}{c}\text { Liquid Transport Coefficient } \\
\mathrm{Dl}(\mathrm{W})\end{array}$ & $\mathrm{Dl}(\mathrm{W})=\mathrm{Dl}\left(\mathrm{w}_{\mathrm{f}}\right) \cdot 10^{3(\mathrm{w} / \mathrm{wf}-1)}$ & $\begin{array}{l}\lg \left(\mathrm{Dl}_{\text {ins }}\left(\mathrm{w}_{0}\right)\right)=-11,-10,-9,-8 \\
\lg \left(\mathrm{Dl}_{\mathrm{OSB}}\left(\mathrm{w}_{0}\right)\right)=-15,-14,-13,-12\end{array}$ \\
\hline $\begin{array}{c}\text { Thermal Conductivity } \\
\lambda(\mathrm{W})\end{array}$ & $\lambda(\mathrm{W})=\lambda\left(\mathrm{w}_{0}\right) \cdot\left(1+\mathrm{b}_{\lambda} \cdot \mathrm{w} / \mathrm{w}_{\mathrm{f}}\right)$ & $\begin{array}{l}\lambda\left(\mathrm{w}_{0}\right)=0.035 \\
\lambda\left(\mathrm{w}_{\mathrm{f}}\right)=0.035,0.105,0.175,0.245\end{array}$ \\
\hline
\end{tabular}

The global sensitivity measure is determined by the absolute mean value $\mu_{i}{ }^{*}$ over the $r$ elementary effects $\mathrm{EE}_{\mathrm{i}}$ of the $\mathrm{i}^{\text {th }}$ parameter. Input parameters associated with high $\mu^{*}$ value are more sensitive to the output ( $\mathrm{rH}$ in the construction at position 1 and 2, Fig. 2). In this study $\mathrm{r}=50$ trajectories are chosen for the $\mathrm{k}=13$ parameters. 50 trajectories showed in this study a good compromise between $\mu_{\mathrm{i}}{ }^{*}$ convergence and simulation effort, i.e. $\mu_{\mathrm{i}}{ }^{*}$ does not change any more in terms of parameter raking when using more than 50 trajectories [7].

The hygrothermal simulations are carried out by means of DELPHIN. The initial conditions and construction dimensions are kept constant. The input parameters are varied by changing the DELPHIN project file and the DELPHIN material parameter files using a similar approach as in $[8,9]$. The moisture-dependent liquid transport coefficient $\mathrm{Dl}$ and thermal conductivity $\lambda$ are approximated in Table $2[10,11]$.

The construction is simulated separately with three-month seasonal summer (June until August) and winter (October until December) weather data provided by WUFI ${ }^{\circledR}$ Pro, in order to consider the different climate conditions in summer and winter. The SA is carried out with the monthly average $\overline{\mathrm{rH}}$ for August and December (the hottest and the coldest months in summer / winter season). In total 1400 simulations (700 runs for summer and for winter) are carried out. The results of the method of Morris are shown in Fig. 3:

- In August $\mathrm{T}_{\text {in }}$ is more sensitive, while in December $\mathrm{rH}_{\text {in }}$ is more sensitive. In August the decreased $T_{\text {in }}$ causes the increased temperature difference between outdoor and indoor air which motivates the reversed water vapor diffusion from exterior to interior. In December the increased $\mathrm{rH}_{\mathrm{in}}$ causes the increased amount of water vapor penetrating into the construction.

- In August the material parameters $\mu_{\text {ins out }}, \mathrm{Dl}_{\text {ins out }}$ and $\mu_{\mathrm{m} \text { out }}$, i.e. the materials outside of the OSB, are the most sensitive parameters. In December, $\mu_{\text {ins in }}, \mathrm{Dl}_{\text {ins in }}$ and $\mu_{\mathrm{m}}$ in are sensitive 
material parameters. In addition, $\mu_{\text {ins out }}$ is an important parameter in December, as well. $\mu_{\mathrm{OSB}}$ is important for both months.

- In December air infiltration I is moderate influential. Because, the temperature on OSB in the reference construction is not significantly below the indoor temperature.

- The moisture-related thermal conductivity $b_{\lambda}$ of insulation material has no influence in August and in December. This parameter is only influential at nearly $100 \%$ of rH, which rarely occurred in the simulations.
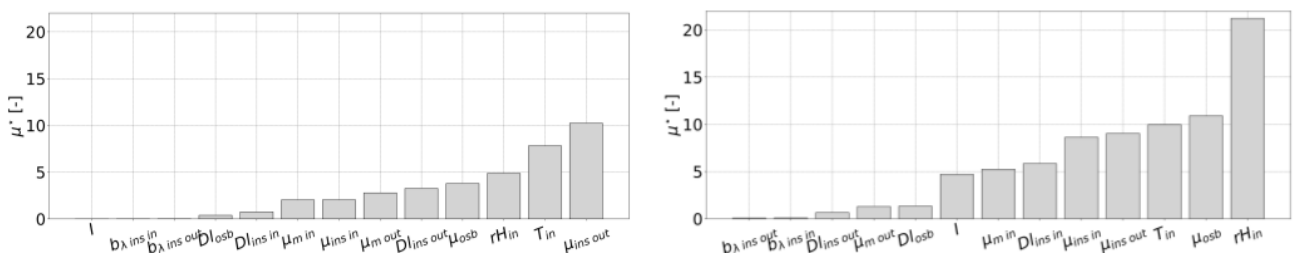

Fig. 3. The $\mu_{\mathrm{i}}{ }^{*}$ calculated by the method of Morris for $\mathrm{rH}$ on the OSB under August (left) and December weather conditions (right)

\section{Identification of Pareto-optimal material parameter set}

In the following a simplified, scalar objective $\overline{\mathrm{rH}}$ (temporal average relative humidity) is used to visualize the best trade-off designs for August and December. $\overline{\mathrm{rH}}$ is calculated based on the hourly available maximum $\mathrm{rH}$ values at the inner and outer side of the OSB structure (position 1 and 2, Fig. 2). By calculating the temporal average, significant hourly fluctuations of $\mathrm{rH}$ within the investigated months are damped, which simplifies the hygrothermal performance comparison between August and December. In addition, shortterm violations of the $\mathrm{rH}$ limit in the construction are acceptable [12] and with the simplified approach robust Pareto-optimal set can be determined.

The insensitive parameters from the section 3 are fixed. Additionally, it is assumed that the planner has chosen a specific type of OSB material with defined material parameters, neglecting material parameter uncertainties, i.e. OSB material parameters are kept constant. The three indoor climate conditions, $22^{\circ} \mathrm{C} / 30 \%, 22^{\circ} \mathrm{C} / 60 \%, 28^{\circ} \mathrm{C} / 60 \%$, are chosen in such a way that the influence of both temperature and humidity can be evaluated. In order to consider the actual state of wall configuration depending on workmanship, the influence of air infiltration is visualized by simulation of two air infiltration levels, $\mathrm{I}=1 \mathrm{~m}^{3} / \mathrm{m}^{2} \mathrm{~h}$ and $\mathrm{I}=5$ $\mathrm{m}^{3} / \mathrm{m}^{2} \mathrm{~h}$.

The six material parameters $\mu_{\mathrm{m} \text { out }}, \mu_{\mathrm{m} \text { in }}, \mu_{\text {ins out }}, \mu_{\text {ins in }}, \mathrm{Dl}_{\text {ins out }}, \mathrm{Dl}_{\text {ins in }}$ are finally varied within defined limits - see Table 1 bold values. The six material parameters are sampled within the defined limits by means of Latin Hypercube sampling approach, which is often used in Design of Experiment (DOE) as an efficient method to generate randomized parameter samples, covering the whole parameter space within the given range [13]. 600 different material parameter combinations are simulated for each boundary condition combination $(3 * 2$ combinations) in summer (June until August) and winter (October until December $)$, i.e. in total $600 *(3 * 2) * 2=7200$ simulation runs are carried out.

The results are shown in Fig. 4 by a scatter plot. Each dot represents one $\overline{\mathrm{rH}}$ value. The abscissa shows the defined objective $\overline{\mathrm{rH}}$ for August, while the ordinate shows $\overline{\mathrm{rH}}$ for December. Depending on the indoor climate condition the results of $\overline{\mathrm{rH}}$ can vary significantly. In December an increase of $\mathrm{rH}_{\text {in }}$ from $30 \%$ to $60 \%$ can lead to an increase of $\overline{\mathrm{rH}}$ at the OSB surface, while in August an increase of $\mathrm{T}_{\text {in }}$ from $22^{\circ} \mathrm{C}$ to $28^{\circ} \mathrm{C}$ decreases $\overline{\mathrm{rH}}$ in most cases. Increase from $\mathrm{I}=1$ to $5 \mathrm{~m}^{3} / \mathrm{m}^{2} \mathrm{~h}$ at $\mathrm{rH}_{\mathrm{in}}=60 \%$ leads to increase of $\overline{\mathrm{rH}}$ in December. 
The curves in Fig. 4 show the Pareto-optimal set, i.e. on these curves one objective (low $\overline{\mathrm{rH}}$ in August / in December) cannot be further improved without having a detrimental effect on the other. In Fig. 4 the minimum $\overline{\mathrm{rH}}$ values are marked by $\mathrm{S} 1,2,3$ and $\mathrm{W} 1,2,3$ for August and December. The median $\overline{\mathrm{rH}}$ values are marked with $\mathrm{Y} 1,2,3$.

The optimized material parameters for each of three markers are visualized by a parallel coordinate plot, Fig. 5:

- Comparing $\mu_{\mathrm{m} \text { out }}, \mu_{\text {ins out }}$ with $\mu_{\mathrm{m} \text { in }}, \mu_{\mathrm{ins}}$ in in August and December, in August the materials deposed outside of OSB are more water-vapor-diffusion-resistant, whereas in December the materials deposed inside of OSB are more water-vapor-diffusion-resistant.

- In August the optimized material parameters are changed depending on $\mathrm{T}_{\mathrm{in}}$, not on $\mathrm{rH}_{\mathrm{in}}$. $\mu_{\text {ins in }}$ is more water-vapor-diffusive for decreased $T_{\text {in. }}$. In December, on the other hand, the optimized material parameters are changed depending on $\mathrm{rH}_{\mathrm{in}}$, not on $\mathrm{T}_{\mathrm{in}}$. Materials deposed inside of OSB are more water-vapor-diffusive for decreased $\mathrm{rH}_{\mathrm{in}}$.

- Fig. 5 right shows the trade-off between the optimized material parameters for August and December, leading to moderate $\overline{\mathrm{rH}}$ values for the whole year.
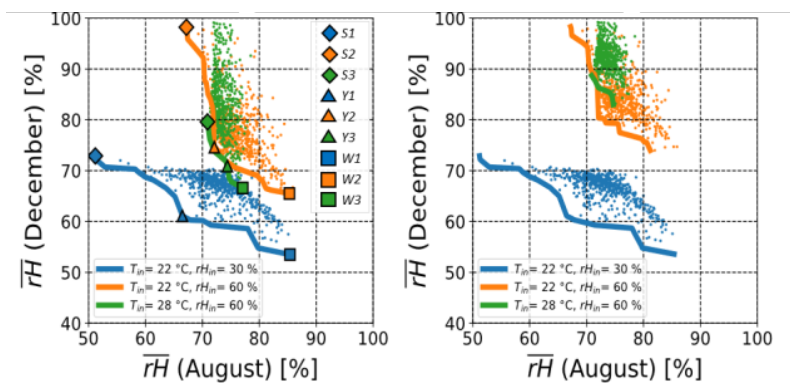

Fig. 4. Mean relative humidity $\overline{\mathrm{rH}}$ in August and in December under three indoor conditions $22^{\circ} \mathrm{C} / 30 \%, 22^{\circ} \mathrm{C} / 60 \%, 28^{\circ} \mathrm{C} / 60 \%$ and air infiltration $\mathrm{I}=1$ and $5 \mathrm{~m}^{3} / \mathrm{m}^{2} \mathrm{~h}$ (left/right). Three Paretooptimal sets are marked in the figure left for August $(\mathrm{S} 1,2,3) /$ December $(\mathrm{W} 1,2,3) /$ entire year $(\mathrm{Y} 1,2,3)$

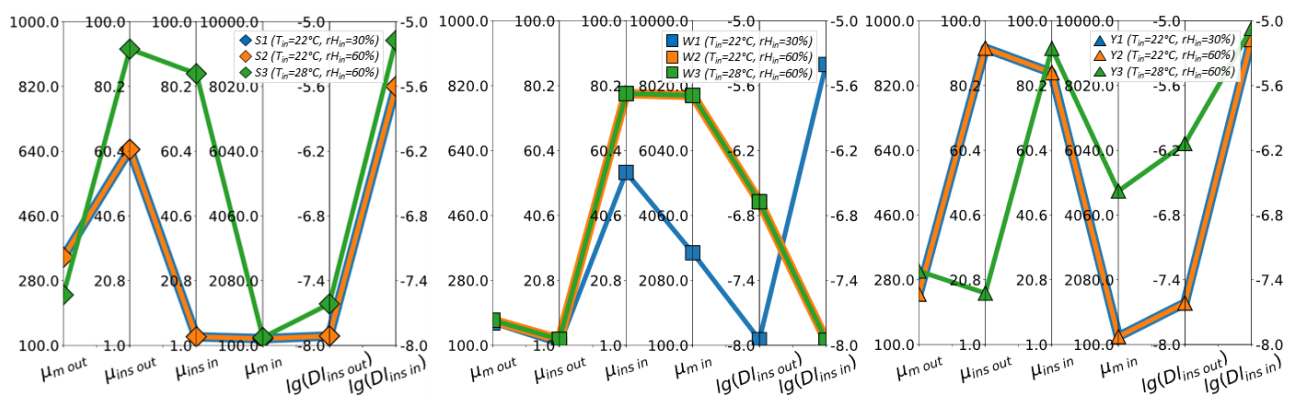

Fig. 5. Parallel coordinate plot of Pareto-optimal material parameter sets for August (S1,2,3, left) / December (W1,2,3, middle) / entire year (Y1,2,3, right) for three indoor conditions $22^{\circ} \mathrm{C} / 30 \%$, $22^{\circ} \mathrm{C} / 60 \%, 28^{\circ} \mathrm{C} / 60 \%$ 


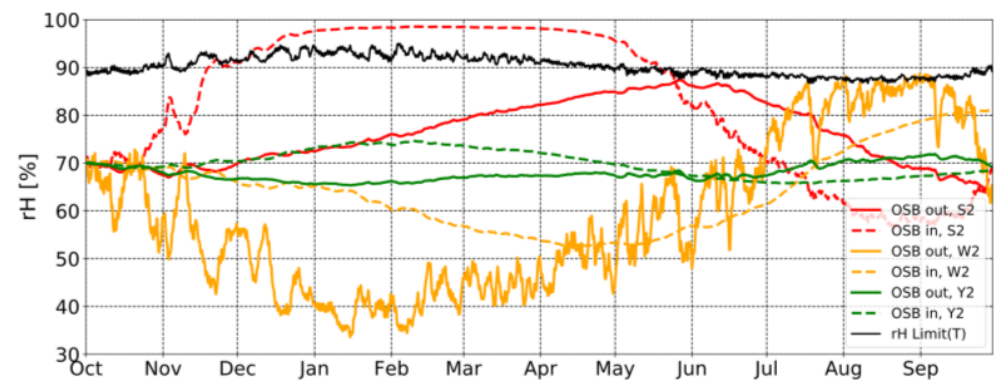

Fig. 6. Hourly $\mathrm{rH}$ on the out-/inside of OSB surface (solid line/dashed line) in August S2 (red) / December W2 (orange) / entire year Y2 (green) optimized constructions and the temperaturedependent $\mathrm{rH}$ limit (black)

Fig. 6 shows three simulations for $\mathrm{rH}_{\text {in }}=60 \%, \mathrm{~T}_{\text {in }}=22^{\circ} \mathrm{C}, \mathrm{I}=1 \mathrm{~m}^{3} / \mathrm{m}^{2} \mathrm{~h}$ and the optimized material parameter configurations $(\mathrm{S} 2, \mathrm{~W} 2, \mathrm{Y} 2)$. The black curve shows the temperaturedependent $\mathrm{rH}$ limit as given by WTA $[12,14]$ : $\mathrm{rH}$ of the pore air in solid wood products must not exceed $95 \%$ at $0^{\circ} \mathrm{C}$ and $86 \%$ at $30^{\circ} \mathrm{C}$ to avoid a risk of wood rot fungi, except for short-term violations of the limit. A rH reduction by more than $15 \%$ could be accomplished with the $\mathrm{Y} 2$ material parameter set compared to the S2 and W2 material parameter sets. Only the Paretooptimal material parameter set for the year Y2 leads to $\mathrm{rH}$ values on OSB significantly below the rH limit.

\section{Conclusion}

The results of sensitivity analysis of the investigated reference construction are different in August and in December because of the opposite water vapor transfer direction: in August from exterior to interior and in December from interior to exterior. Depending on the indoor climate conditions, air infiltration and the range of the six optimized material parameters $\left(\mu_{\mathrm{m} \text { out }}, \mu_{\mathrm{m} \text { in }}\right.$, $\left.\mu_{\text {ins out }}, \mu_{\text {ins in }}, \mathrm{Dl}_{\text {ins out }}, \mathrm{Dl}_{\text {ins in }}\right)$, the mean relative humidity values on the surface of OSB vary within a wide range: $51.2 \%$ - $85.9 \%$ (August), $53.5 \%$ - 99.1 \% (December), see Fig. 4 . The optimized set of material parameter values, identified by means of the Pareto-optimal solution, show the opposite tendency under summer and winter climate conditions. The summer optimized set of material parameters is not appropriate for winter climate data and vice versa. Solely, the trade-off material parameters (Fig. 5 right) lead to low $\mathrm{rH}$ values at OSB for the whole year. In this study, sensitive parameters and good design choices could be found with a reasonable effort. A hygrothermal tool, extended by a sensitive analysis and design of experiment framework, could be supportive for the planner to draw conclusion about optimal designs.

\section{References}

1. ISO 13788: Hygrothermal performance of building components and building elements - Internal surface temperature to avoid critical surface humidity and interstitial condensation - Calculation methods (2013)

2. P. Leusden, F. Freymark, Darstellung der Raumbehaglichkeit für den einfachen praktischen Gebrauch, Gesundheitsingenieur 72, Heft 16 (1951)

3. Government of Korea, 건축물의 에너지절약설계기준 제 2017-881 호 (Energy-saving building design standards 2017-811), Ministry of Government Legislation (2017)

4. A. Saltelli, M. Ratto, T. Andres, Global Sensitivity Analysis: The Primer, John Wiley \& Sons Ltd (2008)

5. F. Pianosi, K. Beven, J. Freer, J. Hall, J. Rougier, D. Stephenson, T. Wagener, Sensitivity analysis of environmental models: A systematic review with practical workflow, Environmental Modelling \& Software 79, P.214-232 (2016) 
6. M.Morris, Factorial Sampling Plans for Preliminary Computational Experiments, Technometrics 33 (2), P.161-174 (1991)

7. F. Sarrazin, F. Pianosi, T. Wagener, Global Sensitivity Analysis of environmental models: Convergence and validation, Environmental Modelling and Software 79, P.135-152 (2016)

8. A. Nicolai, Automated Variation Studies with DELPHIN using Python, A DELPHIN Tutorial from www.bauklimatik-dresden.de (2008)

9. J. Zhao, R. Plagge, A. Nicolai, J. Grunewald, S. Zhang, Stochastic study of hygrothermal performance of a wall assembly, HVAC\&R Research 17(4), P.591-601 (2011)

10. K. Kieß1, Kapillarer und dampfförmiger Feuchtetransport in mehrschichtigen Bauteilen, Dissertation, Universität-Gesamthochschule Essen (1983)

11. H. Kuenzel, Simultaneous heat and moisture transport in building components, Universität Stuttgart (1995)

12. WTA-Merkblatt 6-8-15, Feuchtetechnische Bewertung von Holzbauteilen - Vereinfachte Nachweise und Simulation, Fraunhofer IRB Verlag (2016)

13. K. Siebertz, T. Hochkirchen, Statistische Versuchsplanung: design of experiments (DoE), Springer (2010)

14. D. Kehl, Feuchtetechnische Bemessung von Holzkonstruktionen nach WTA, Holzbau 6/2013, P.24-28 (2013) 